\title{
The effect of different suckling feeding modes on the growth and development of calves in postnatal ontogenesis
}

\author{
Tatyana Sedykh ${ }^{1,2, *}$, Idris Yumaguzin $^{1}$, Albina Aminova ${ }^{1}$, Rinat Gizatullin ${ }^{3}$, and Vladimir \\ Kosilov $^{4}$ \\ ${ }^{1}$ Ufa Federal Research Center of the Russian Academy of Sciences, Bashkir Research Institute of \\ Agriculture, Ufa, Russia \\ ${ }^{2}$ Federal State Budgetary Educational Institution of Higher Education Bashkir State Pedagogical \\ University named after M. Akmulla, Ufa, Russia \\ ${ }^{3}$ Federal State Budgetary Educational Institution of Higher Education Bashkir State Agrarian \\ University, Ufa, Russia \\ ${ }^{4}$ Federal State Budgetary Educational Institution of Higher Education Orenburg State Agrarian \\ University, Ufa, Russia
}

\begin{abstract}
One of the key areas of development of the cattle breeding industry in Russia is the creation of effective technological methods. They allow to carry out the improvement and establishment of new resourcesaving systems for breeding young animals at an accelerated pace. It is essential to meet the modern requirements of meat production as an ecologically safe product. The aim of the research was to enhance the fattening qualities of Hereford bull calves while using mode-setting suckling of various ratios as an element of resource saving. The study was performed on "SAVA-Agro-Yapryk" OOO of the Tuymazinsky district of the Republic of Bashkortostan. The determination of the efficiency of the use of free and mode-setting suckling of various ratios made it possible to identify an effective method of raising young meat cattle. A three-fold mode suckling is used with separate keeping of young animals and mother cows. This makes it possible to keep the optimal microclimate parameters in the calf house, contributes to the rapid early adaptation of calves to the consumption of coarse feed and concentrates. It has a positive effect on the growth and development of calves and their meat productivity at the age of 18 months according to the parameters of removable fat mass, carcass mass and interior fat mass. All this promotes an increase in the sale of beef and an improvement in the level of production profitability to $13.93 \%$.
\end{abstract}

\section{Introduction}

The growing output of high-quality products is a challenge that has not lost its relevance over the years. Due to the increase in the population of our planet, the problem of nutrition with high-grade and high-quality products is increasing. For this reason, great importance is

\footnotetext{
* Corresponding author: sci_secr_bniish@bk.ru
} 
attached to the development of the cattle breeding industry. One of the key areas of development of the cattle breeding industry in Russia is the creation of effective methods of rearing young animals. They will allow for accelerated improvement, and the creation of new systems for rearing young animals that meet the modern requirements of meat production as an ecologically safe product $[2,3,7,14]$.

It is quite an essential problem to create new forage reserves and to improve the existing ones. Much importance is placed on the zoohygienic requirements for the construction of premises for keeping livestock, the use of modern techniques of mechanization of laborintensive processes and the improvement of technological equipment in cattle farms $[6,8,12,9,15]$.

The improvement of meat production and its quality is an incredibly pressing problem for modern cattle breeding. The growth of the number of specialized meat breeds, the correct arrangement of growing and feeding young animals, as well as the use of resourcesaving elements to decrease the cost of a unit of manufacture should contribute to their solution $[1,4,11,13,17]$.

Russian researchers have performed a number of comparative studies of the formation of meat productivity of young animals using various methods of suckling breeding. Several variants of the mode-setting suction are described. For example, Oguy V. G and Shevchenko N. I. from the Altai State Agrarian University point out that the calf is tamed to independently suck milk from the udder, then it is transferred to a group cage and allowed to consume cow milk for 10-20 minutes three times a day. The calves are isolated from cows at the age of six months with an average live weight of $160 \mathrm{~kg}$. This breeeding technique ensures a rather high preservation of the calves (99.64\%) [10]. Makharinets G. G. and Dobrelin V. I. from the Don Research Institute of Agricultural Sciences note that in the study of the biochemical composition of the blood of calves of the Kalmyk breed kept on mode-setting suction and getting calf starter as part of the diet, a higher content of protein and its fractions as well as hemoglobin was found in all age periods. This fact to a certain extent contributed to a better increase in live weight. It was revealed that the young animals of this group at the age of 6 months outperformed their herdmates in terms of live weight by $34.5 \%$ [8]. The technique described by I. V. Shchukina (Kuban State Agrarian University), F. G. Kayumov and B. G. Rogachev (All-Russian Scientific Research Institute of Metrological Service) can be attributed to modern technologies of growing beef breed cattle. These researchers point out the high efficiency of raising calves of highly productive beaf breeds on suckling under cows of steers-up to 6 months and heifers-up to 8 months using lightweight-type premises with a regulated microclimate, equipped with a recreation area on a deep litter, directional feeders while providing free access to the feeding cows in the paddock yard [13].

Therefore, the aim of the research was to enhance the fattening qualities of Hereford bull calves when using mode-setting suckling of various ratioss as a resource-saving element. The objectives included: to study the features of the technology of keeping, including the characteristics of the microclimate, and feeding of young Hereford breed with the use of mode-setting suckling of various ratios; to study the parameters of the clinical and physiological status, growth and development of steers with the use of mode-setting suckling of various ratios, to study the indicators of meat productivity of steers raised with the use of mode-setting suckling of various ratios in the early postnatal period; to define the economic efficiency of the use of mode-setting suckling of various ratios.

\section{Materials and methods}

The research and economic test was performed in SAVA-Agro-Yapryk OOO of the Tuymazinsky district of the Republic of Bashkortostan. The object of research was 
purebred Hereford bulls, the 5th generation of domestic reproduction, derived from cattle imported from Australia. In order to study the efficiency of the use of mode-setting suction of various ratios as a resource-saving element by the method of pairs-analogues in terms of live weight and development, 3 experimental groups were formed by newborn calves $(n=10)$ born from mother cows of the third calving. Calves were kept together with their mothers in the control group until the age of 6 days in the experimental groups and before pasture in the control group (free suckling) [11]. Furthermore, from the age of 6 days, the young bulls of the control group continued to be on free suction, the young bulls of the 2nd and 3rd experimental groups used 2 and 3-fold mode-setting suction, respectively. The mother cows were kept 24 hours a day on the card and were allowed to go to the calves only for the time of suckling. Since the end of May, bulls with mother cows have been grazing on pastures. The young bulls were grown up to 7-8 months of age at the suckling stage, then they were ridden off their mothers and put on rearing with subsequent fattening.

The microclimate settings of the premises were identified according to generally accepted methods. We measured the air temperature and humidity using a psychrometer. As for humidity, it was calculated using a hygrometer. The carbon dioxide content was defined by the modified Subbotin-Nagorsky method (Moscow State Academy of Veterinary Medicine and Biotechnology named after K. I. Scriabin), ammonia and hydrogen sulfide were determined by the UG-1 gas analyzer. The air velocity was measured by a hydrometer, and the illumination - by a luxometer.

The growth and development of calves were considered by monthly weighing of newborn calves at the age of 2, 4, 6, 8, and 18 months. Meanwhile, the absolute and average daily weight gain, the relative growth rate, as well as the main body indices were calculated. For the study of meat productivity, a control slaughter of young bulls at the age of 18 months was performed. Slaughter indicators were examined in three animals from each group. The obtained research findings were processed by the biometric method using a personal computer and Microsoft Excel 2000.

\section{Results and discussion}

The condition of the microclimate in the livestock premises where the calves are kept was considered by generally accepted methods twice at the beginning and at the end of the dairy period. The evaluation was performed to identify various technological methods of growing for the microclimate of the space.

In accordance with the data on the microclimate of the premises where the calves were kept, it can be noted that the parameters worsened when the mother cows and calves were kept together. In this regard, the relative humidity index outperformed the standard ones in the cages for calves up to 3 months of age by $2 \%$, the indicators of ammonia content-by 2 $\mathrm{mg} / \mathrm{m}^{3}$, carbon dioxide - by $6 \mathrm{mg} / \mathrm{m}^{3}$. It should be mentioned that ammonia is easily dissolved in the air and has an irritating effect on the mucous membranes of the nasopharynx, upper respiratory tract and conjunctiva of the eyes.

The analysis of the feed resources indicates that the diets used fully covered the regulatory needs of mother cows and suckling calves in nutrients. The table data show a higher feed consumption by calves of the 2 nd experimental group raised on 3 -fold suckling. In this case, milk consumption is 5\% higher than in the control group and $7.2 \%$ less than with two-fold suckling. Notwithstanding the lower milk consumption, the calves of the 1 st experimental group had a higher feed consumption than in the control group, where the herdmates were on free hay sucking - by $10.8 \%$, and as a result of better adaptation to coarse feeds and pasture greens - by $11.0 \%$. The calves of the 2 nd experimental group, which were on 3 -fold suckling for 8 months of growing, consumed more milk - by $5.5 \%$; hay $-12.7 \%$; green mass - by $16.5 \%$ compared to those on free suckling. 
Additionally, the use of mode-setting suckling and isolated keeping of mother cows and calves, first of all, significantly reduces the cost of labor and bedding material for rearing young animals and, secondly, provides better zoohygienic conditions for calves. The modesetting suckling stimulates the rapid adaptation of calves to coarse feeds and good feedability of hay and top dressing in the form of a concentrate mixture, which in turn promotes better development of the gastrointestinal tract at an earlier age. We observed all this in experimental groups. Meanwhile, the calves in the control group on free suckling ate coarse feed worse. The calves have the opportunity to receive mother's milk in small portions up to 6-8 times a day when they are kept together. This improves the digestibility of milk and contributes to a more intensive growth of calves in the first months of the postnatal period compared to calves on mode-setting suckling, as shown by the data in Figure 1. Nevertheless, such a tendency was observed in the first 2-3 months of growth of the young animals of the control group. Later, the calves which were on mode-setting suckling had a rapid development of cicatricial digestion, due to the fast adaptation to coarse feeds and concentrates. Moreover, they began to increase the live weight more intensively.

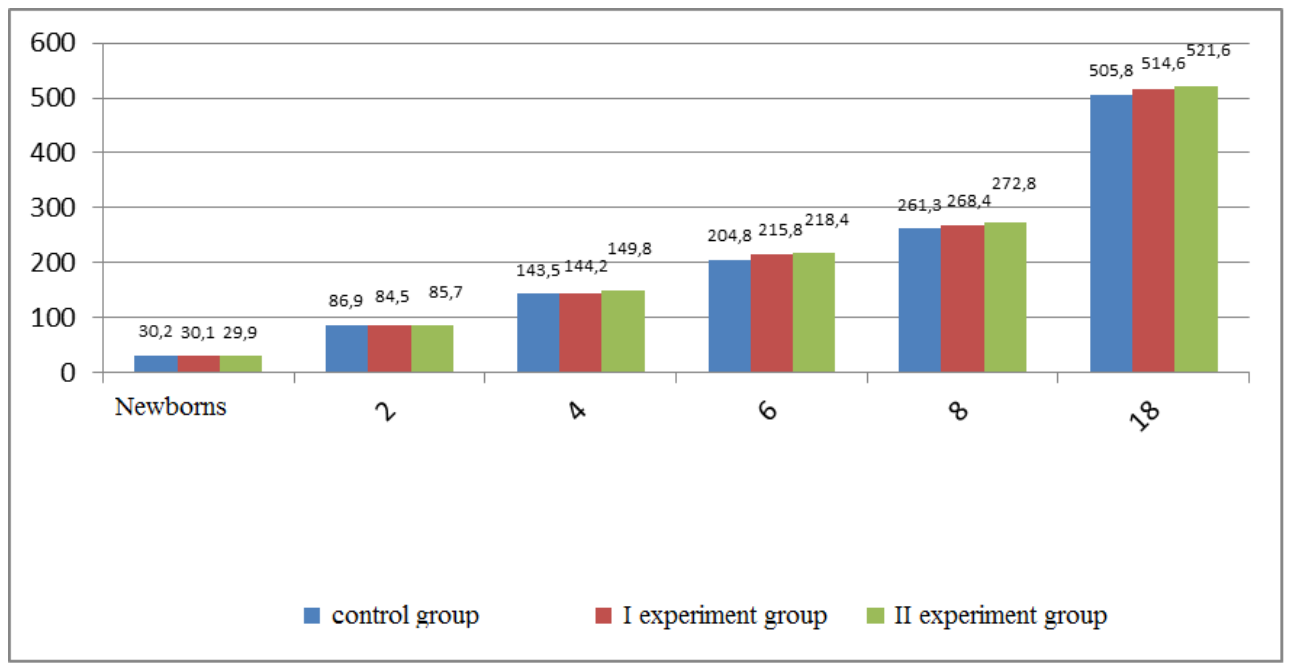

Fig. 1. Dynamics of live weight of young bulls.

The data on the dynamics of live weight indicate a significant $(\mathrm{P} \leq 0.05)$ grow in live weight in the young bulls of the 2nd experimental group at 8 and 18 months of age. Therefore, the weight of young animals in this group exceeds the control and 1 experimental group starting from the age of 4 months, at first slightly by $4.3 \%$ and $3.9 \%$; in the 6 -month - by $6.6 \%$ and $1.2 \%$; in the 8 -month-significantly by $4.4 \%$ and $4.2 \%$; in the 18 -monthsignificantly by $3.1 \%$ and $1.4 \%$, respectively. It should be noted that by the end of the fattening period, the live weight of animals of the experimental groups did not differ significantly.

Weight growth indicators are described by a number of parameters, such as absolute and average daily live weight gains, which characterize the growth and development of tissues and organs of the body, along with body weight gauges and index of body built. Total live weight gains describe the increase over a certain period of time and over the entire period of growth. The table shows that the growth of the young animals of the experimental groups as a whole occurred evenly. The highest absolute increases from birth to 8 months of age were established in the 2nd experimental group and outperformed the control group with reliability at $\mathrm{P} \leq 0.05$ by $8.18 \%$ and from birth to 18 months of age-by $3.4 \%$. This 
shows the influence of the 3 -fold regulated suction on the absolute increases in the live weight of the Herefodian young bulls.

Generally, the average daily gains increase fairly equally over the age periods, which indicates the balanced growth and development of the body of young animals. The bbiggest average daily gains are observed in the period from birth to 2 months of age in the control group, in the consequent period - in the young bulls of the 2nd experimental group. Yet, their significant increase compared to the control group was determined for the period from 6 to 8 months of age - by $8.72 \%$; in the period from birth to 8 months of age-by $8.21 \%$; from birth to 18 months of age - by $3.3 \%$. The obtained data show a significant impact of the use of 3-fold mode-setting suckling on the growth of live weight in the initial period of development (from birth to weaning from mothers). In the future, with intensive fattening, this effect remains. During the growth period from birth to 8 months and from birth to 18 months of age, the relative growth rate of young calves with 3-fold regulated suckling was insignificantly higher than in the 1st experimental and control group.

The indicators of meat productivity describe the post-slaughter qualities of the carcasses of young bulls, and give a more complete picture of the meat qualities than the indicators of live weight and gains.

The results of the control slaughter are given in the table 1.

Table 1. The results of the control slaughter of the young bulls.

\begin{tabular}{|l|c|c|c|}
\hline \multirow{2}{*}{\multicolumn{1}{|c|}{ Indicator }} & \multicolumn{3}{c|}{ Group } \\
\cline { 2 - 4 } & control & I experimental & II experimental \\
\hline Removable live weight, $\mathrm{kg}$ & $506.9 \pm 4.2$ & $515.6 \pm 5.1$ & $522.7 \pm 5.1^{*}$ \\
\hline Pre-slaughter live weight, kg & $491.6 \pm 5.3$ & $498.7 \pm 3.4$ & $506.0 \pm 3.9$ \\
\hline Carcass weight, kg & $284.1 \pm 1.2$ & $291.2 \pm 2.8$ & $295.0 \pm 1.5^{*}$ \\
\hline Interior fat mass, kg & $11.3 \pm 0.420$ & $11.5 \pm 0.4$ & $12.5 \pm 1.2^{*}$ \\
\hline Dressed weight, kg & $295.3 \pm 3.2$ & $302.73 \pm 2.2$ & $307.5 \pm 2.0$ \\
\hline Carcass yield, \% & $58.0 \pm 0.9$ & $58.2 \pm 0.8$ & $58.3 \pm 0.9$ \\
\hline Fat yield, \% & $2.3 \pm 0.3$ & $2.3 \pm 0.5$ & $2.5 \pm 0.2$ \\
\hline Slaughter yield, \% & $60.0 \pm 1.1$ & $60.5 \pm 2.1$ & $60.8 \pm 1.0$ \\
\hline
\end{tabular}
$\mathrm{P} \leq 0.05$

The results of the control slaughter demonstrate that the young bulls grown using 3-fold mode-setting suckling significantly $(\mathrm{P} \leq 0.05)$ overtop the herdmates of the control group in terms of removable live weight (by $3.12 \%$ ), carcass weight (by $4.19 \%$ ) and interior fat weight $(10.99 \%)$. According to other indicators: pre-slaughter live weight, dressed weight, carcass yield, fat yield and slaughter yield, the 1st experimental group slightly outperforms the control by $1,63 \% ; 2,53 \% ; 02,5 \% ; 0,01 \%: 0,53 \% ; 2$-the experimental group exceeds the control group by the same indicators - by $3,12 \% ; 4,50 \% ; 0,6 \% ; 0,17 \% ; 0,8 \%$.

Therefore, in general, we can say that we did not find a significant difference in the studied indicators of the control slaughter, with the exception of the removable live weight, carcass weight and interior fat mass. This means that the indicators of meat productivity between groups of young bulls, in which free and mode-setting suckling of various ratios was used in the early suckling period. In the process of intensive fattening, they can be leveled.

The substantiation of the economic efficiency of the use of mode-setting suckling of various ratios in the breeding of Hereford young bulls is given in the table 2 . 
Table 2. Economic efficiency of the use of mode-setting suckling of various ratios in the breeding of Hereford young bulls.

\begin{tabular}{|l|c|c|c|}
\hline \multirow{2}{*}{\multicolumn{1}{|c|}{ Indicator }} & \multicolumn{3}{c|}{ Group } \\
\cline { 2 - 4 } & control & I experimental & II oexperimental \\
\hline Livestock in the group, heads & 10 & 10 & 10 \\
\hline Livability, \% & 100 & 100 & 100 \\
\hline Sold meat in carcasses, hundredweight & 28.3 & 29.0 & 29.5 \\
\hline Total costs, thousand rubles. & 543.5 & 546.1 & 548.9 \\
\hline $\begin{array}{l}\text { Revenue from the sale of beef, thousand } \\
\text { rubles. }\end{array}$ & 600.2 & 615.3 & 625.3 \\
\hline $\begin{array}{l}\text { Profit from the sale of meat } \\
\text { in carcasses, thousand rubles. }\end{array}$ & 56.7 & 69.2 & 76.5 \\
\hline Profitability, \% & 10.4 & 12.7 & 13.9 \\
\hline
\end{tabular}

The findings of the economic calculations of the use of free and regulated suckling in the rearing of young bulls indicate the economic practicability of using a 3-fold modesetting suckling. Since this technological technique enables to organize earlier and more effective training of calves to eat coarse feed and concentrates, what increases the average daily and absolute accumulations of live weight of calves, both at an early stage of development before the calves are pastured, and in the future. This is clearly shown by the higher removable weight and larger carcass masses at the age of 18 months in the young bulls of this group. All this facilitated the sale of beef in the 2 nd experimental group more than in the control and 1st experimental groups - by $1.19 \mathrm{c}$ or by 25,164 thousand rubles, and by $0.48 \mathrm{c}$ or by 10,091 thousand rubles; increase profit by 19,749 and 7,304 thousand rubles and boost the level of profitability to $13.93 \%$.

Our data are consistent with the results obtained by other scientists. Tikhonov P. T. from the Orenburg State Agrarian University notes that cows of the Kazakh white-headed breed, which are on a mode-setting suckling and grazed separately from calves, during the lactation period allocated an average of $133.2 \mathrm{~kg}$ of milk. It is more than cows grazed together with young animals, since calves, which were together with cows, often distressed them and prevented them from eating food. By the time of weaning from mothers at the age of 8 months, the live weight of the animals grown on the mode-setting suckling was $40.0 \mathrm{~kg}$ higher than the weight of the control animals. On the basis of all the above, the author argues that the separate keeping of cows and calves with the use of mode-setting suckling has a positive effect on the growth and development of calves and provides an opportunity to get a higher live weight of young animals for weaning from mothers [16]. Korovin A. N. and Kibalko A. I. from the Kursk State Agricultural Academy studied young animals of the Simmental breed and found that young bulls raised on mode-setting suckling had a preslaughter weight $14.7 \mathrm{~kg}$ higher at the age of 18 months, and their herdmates on free suckling were $8.1 \mathrm{~kg}$ higher than animals on hand-fed. In the same group (mode-setting suckling), high indicators of the absolute content of muscle tissue, the specific weight of the pulp to the mass of the carcass $(79.2 \%)$ and other indicators of meat productivity were observed [5]. In previous studies, the authors found that young bulls on mode-setting suckling are easier to tolerate weaning from their mothers.

\section{Conclusion}

Therefore, the determination of the effectiveness of the use of free and mode-setting suckling of various ratios allowed us to identify an effective method of raising young meat cattle, which is a 3 -fold mode suckling, with separate keeping of young animals and mother 
cows. It enables to preserve the optimal microclimate parameters in the calf house, contributes to the rapid early adaptation of calves to the consumption of coarse feed and concentrates, and further has a positive effect on the growth and development of calves and their meat productivity at the age of 18 months in terms of removable live weight, carcass weight and interior fat mass. All this contributes to an increased sale of beef and an improvement in the profitability of production to $13.93 \%$.

\section{References}

1. A. Jafari, A. Azarfar, G. M. Alugongo, G. R. Ghorbani, M. Mirzaei, A. Fadayifar, H. Omidi-Mirzaei, Z. Cao, J. K. Drackley \& M. Hossieni Ghaffari, It J of An Sc, 20(1), 336-351 (2021)

2. N.V. Bykovskaya, A.A. Kormilitsina, Bul of the Rus St Agr Cor Un, 24 (29), 34-38 (2017)

3. S.Y. Elsanat, M.A. Abu El-Hamd, Mervat E. El-Demery, A.M. Salama, J of F \& D Sc, 2(3), 143-158 (2011)

4. J. Kulpys, A. Januškevičius, J. Černauskiene, Ve ir Zoot, 50(72), 48-53 (2010)

5. L.I. Kibalko, A.N. Korovin, Ag sc, 8, 31-32 (2009)

6. A.N. Korovin, L.I. Kibalko, Bul of the Kur St Agric Ac, 5, 66-69 (2009)

7. T.S. Kubatbekov, Y.A. Yuldashbaev, H.A. Amerkhanov, A.A. Salikhov, V.I. Kosilov, F.M. Radjabov, H.B. Garyaev, Ad in An and Vet Sc, 8 (3), 38-42 (2020)

8. G.G. Makharinets, V.I. Dobrelin, Veterinary pathology, 41 (3), 73-77 (2012)

9. M. Domaćinović, Z. Antunović, M. Šperanda, P. Mijić, I. Klarić, D. Bagarić, Mljekarstvo, 59 (4), 296-301 (2009)

10. V.G. Ogui, N.I. Shevchenko, Bul of the Alt St Agr Un, 3(15), 314-315 (2004)

11. A.R. Salikhov, A.R. Salikhov, T.A. Sedykh, R. S. Gizatullin, Izv of the Sam St Agr Ac, 1, 138-141 (2015)

12. T.A. Sedykh, R.S. Gizatullin, F res, 2-18, 3971-3975 (2015).

13. I.V. Shchukina, F.G. Kayumov, B.G. Rogachev, $D \& m$ c br, 7, 20-21 (2015)

14. I.V. Shchukina, A.V. Kharlamov, B.G. Rogachev, Bul of m cat br, 4(82), 56-60 (2013)

15. D. Smakuyev, M. Shakhmurzov, V. Pogodaev, A. Shevkhuzhev, M. Rebezov, V. Kosilov, Zh. Yessimbekov, J of the S S of Agr Sc, 1-6 (2021)

16. P.T. Tikhonov, Izv Or St Ag Un, 1(5-1), 122-124 (2005)

17. L. Vadopalas, E. Zokaityte, P. Zavistanaviciute, R. Gruzauskas, V. Starkute, E. Mockus, J. Klementaviciute, M. Ruzauskas, V. Lele, D. Cernauskas, et al., Animals, 11, 2544 (2021). 